\section{Adverse Cardiovascular Events Due to the Use of NSAIDs and COX-2 Inhibitors - A Review}

\author{
Abhijit $N^{*}$ and Sunjoy Verma \\ Department of Anesthesiology and Critical Care, Citizens Hospital, \\ Hyderabad, India
}

\begin{abstract}
Non-Steroidal Anti-Inflammatory Drugs (NSAIDs) and Cyclo-Oxygenase-2 (COX-2) inhibitors are commonly prescribed analgesic agents for acute post-operative pain and in patients with chronic pain (cancer pain, osteoarthritis etc.,). In many countries, patients use these drugs without supervision as it is easily available over the counter. The cardiovascular adverse effects are described in the product literature in the form of a black box warning. Still practitioners prescribe these drugs rampantly. We reviewed the available literature which described the cardiovascular adverse effects of non-selective NSAIDs and COX-2 inhibitors.

Keywords: Cardiovascular diseases; Cyclooxygenase 2 inhibitors; Myocardial infarction; Non-steroidal anti-inflammatory agents; Stroke
\end{abstract}

\section{Introduction}

NSAIDs (Non-Steroidal Anti-Inflammatory Agents) are the most common over the counter sold and purchased analgesic drugs. These drugs are very popular among people because it is easily available without prescription, provides excellent pain relief and are quite economical, although black box warning for cardiovascular risk is suggested by USFDA.

The classification of non-specific NSAIDs is shown in below (Table 1).

Non-selective NSAIDs suppress COX-1 and 2 therefore although pain with inflammation is relieved due to COX-2 inhibition; it also leads to gastric hyperacidity and anti-platelet action due to inhibition of COX-1 enzyme. Therefore selective COX-2 inhibitors were developed to avoid side effects due to COX-1 inhibition. However, it was noticed that although COX-1 inhibition related problems were reduced, the cardiovascular risk due to COX-2 inhibitors were either the same or more as compared to non-selective NSAIDs.

*Corresponding author: Abhijit Nair, Department of Anesthesiology and Critical Care, Citizens Hospital, Hyderabad, India, Tel: +91 9963180495 E-mail: abhijitnair95@gmail.com

Citation: Abhijit N, Verma S (2015) Adverse Cardiovascular Events Due to the Use of NSAIDs and COX-2 Inhibitors - A Review. J Anesth Clin Care 2: 009.

Received: February 16, 2015; Accepted: July 22, 2015; Published: August 05, 2015

\begin{tabular}{|c|c|c|}
\hline S. No. & Group & Examples \\
\hline 1 & Salicylates & Aspirin \\
\hline 2 & Pyrazolone & Phenylbutazone \\
\hline 3 & Indole derivative & Indomethacin \\
\hline 4 & Propionic acid derivative & Ibuprofen, Naproxen \\
\hline 5 & Aryl acetic acid derivative & Diclofenac, Etodolac \\
\hline 6 & Oxicam derivative & Piroxicam \\
\hline 7 & Pyrollo-pyrolle derivative & Ketorolac \\
\hline
\end{tabular}

Table 1: Classification of non-specific NSAIDs with commonly used agents as examples.

\section{The magnitude of the problem}

The cardiovascular events occurring due to the use of NSAIDs are well described in literature. These risks are heart failure, myocardial infarction, stroke and cardiovascular death. No NSAID is considered to be devoid of risk of these events. The dose and exposure duration that may predispose a patient to cardiovascular events has not yet been defined. McGettigan and Henry collected data on the relative risk of cardiovascular events associated with individual NSAIDs derived from meta-analysis of randomised trials and controlled observational studies. The data was collected from 15 low, middle and high income countries from Intercontinental Medical Statistics Health (IMS Health) or national prescription pricing audit (in the case of England and Canada), pertaining to sale and prescription of NSAIDs. Diclofenac and etoricoxib were the drugs which constituted one third of the NSAID consumption in these countries. They found that diclofenac was the most commonly used NSAID and cardiovascular side effects were seen predominantly with the use of diclofenac, rofecoxib and etoricoxib. They suggested removal of diclofenac from Essential Medical List (EML) [1].

\section{Pharmacodynamics of NSAIDs and COX-2 inhibitors}

NSAID usually act by reversible inhibition of COX-1 and COX-2 eventually leading to inhibition of prostaglandin biosynthesis. The problems encountered with this were sodium retention, hypertension, reduced renal blood flow and subsequent worsening of renal function due to prostaglandin inhibition. The volume overload status due to sodium retention and hypertension by itself leads to congestive heart failure in elderly patients, patients having underlying coronary artery disease. Pre-existing endothelial dysfunction can also be factor responsible for thrombotic events either alone or with other situations described earlier [2]. COX-1 enzyme confers gastroprotective effects, promotes platelet aggregation and preserves renal blood flow by mediating production of prostaglandins and thromboxanes [3]. However, prostacyclin is produced by COX-2 and thromboxane produced by COX-1 have antithrombotic and prothrombotic effects respectively [4]. COX-2 enzyme mediates pain and fever through cytokines released due to inflammation. It also preserves renal blood flow and help in repair of tissues. This led to the development of selective COX-2 inhibitors that selectively interferes with pain pathway and antipyretic effects [5] (Figure 1). 


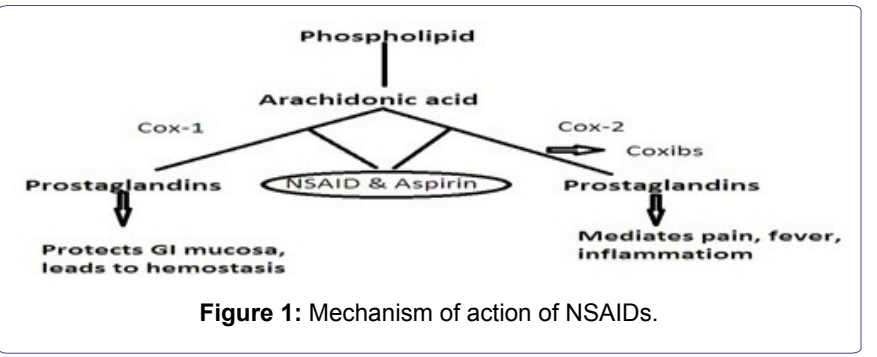

\section{Cardiovascular consequences of $\mathrm{COX}$ inhibition}

Isozymes COX-1 and COX-2 are responsible for the conversion of arachidonic acid to eicosanoids which promotes cardiovascular homeostasis. COX-1 is responsible for the production of thromboxane which leads to platelet aggregation, vasoconstriction and smooth vessel proliferation. On the other hand, prostacyclin produced in vessels has exactly opposite effects of thromboxane. Non-selective COX inhibitors i.e. NSAIDs interfere with this homeostatic mechanism leading to cardiovascular adverse events. By inhibiting COX-2 enzyme selectively, the COX-2 inhibitors promotes cardiovascular events by promoting platelet aggregation and vasoconstriction [6,7]. But selective COX-2 inhibition leads to decreased prostacyclin production, without inhibition of thromboxane produced by COX-1. In this way, the platelet aggregation properties and vasoconstrictive effects of thromboxane are not countered. Pawlosky suggested 5 variables that were responsible for cardiovascular risk of NSAID. They are COX-2 selectivity, dose responsiveness, plasma half-life, blood pressure and interaction with acetyl salicylic acid (ASA) [8].

\section{Review of Literature}

Table 2 summarises several studies which includes retrospective cohort studies, meta analysis of randomised controlled trials and observational controlled studies, population based nested case control studies, multicenter, randomized, placebo-controlled, double-blind trial. The studies included in the review involve thousands of patients who were followed up for the consequences of either non- specific NSAID or COX- 2 inhibitors. The results of the trials and studies are described after the table.

\section{Methods}

We searched Medline and Embase databases using following keywords: Non-Steroidal Anti-Inflammatory Agents, Cyclooxygenase 2 Inhibitors, Cardiovascular Diseases, Myocardial Infarction and Stroke. We reviewed manuscripts which described the adverse effects due to the use of NSAIDs and COX-2 inhibitors in different situations.

\section{Results}

The population based retrospective cohort study conducted by Hudson et al., compared the risk of death and recurrent congestive heart failure in 2256 elderly patients who were prescribed COX-2 inhibitors (Celecoxib, Rofecoxib) and NSAIDs. They concluded from the results that celecoxib had a better profile compared to rofecoxib and other NSAIDs with rofecoxib having a higher risk of death and congestive cardiac failure [9]. Ray et al., conducted a multisite retrospective cohort study involving 48,566 patients recently, hospitalised for myocardial infarction, revascularization and unstable angina. Diclofenac, ibuprofen, naproxen, rofecoxib and celecoxib were the drugs used for pain relief in these patients. The authors felt that among all the above mentioned drugs, Naproxen had a better cardiovascular profile when compared to other NSAIDs and COX-2 inhibitors [10]. Lindhardsen et al., conducted a longitudinal cohort study in 17,320 rheumatoid arthritis patients to examine the risk of cardiovascular diseases in these patients due to NSAID use. 69,280 patients were used as control with 4:1 ratio. 6283 events were noted after around 5 years of follow up. The cardiovascular risk was considerably lower in Rheumatoid Arthritis (RA) patients as compared to control group. More risk was observed in patients who received diclofenac or rofecoxib. Authors felt that NSAID shouldn't be avoided just because of the described adverse cardiovascular effects. The decision of avoiding NSAID should be made after knowing pre-existing co-morbidities especially coronary artery disease or history of heart failure [11]. Graham et al., conducted a nested case-control study to investigate the risk of MI and sudden cardiac deaths in patients treated with COX-2 inhibitors and NSAIDS. They also compared celecoxib and rofecoxib in the same study. Out of 8143 with cardiac issues, 2210 (27.1\%) had fatal cardiac events. On further analysis they reached to a conclusion that rofecoxib was associated with more serious cardiovascular events and that use of naproxen did not protect against occurrence of cardiac events [12]. A population based nested case-control analysis by Hippisley-Cox and Coupland identified 9218 patients who were prescribed NSAID (diclofenac, ibuprofen, naproxen) and COX-2 inhibitors (celecoxib and rofecoxib). The results pointed towards the potential cardiovascular risk conferred by the use of the above drugs. They even concluded that available evidence doesn't support reduced risk of myocardial infarction if naproxen is used [13]. Bresalier et al., conducted the APPROVe trial (Adenomatous Polyp Prevention on Vioxx) which investigated the role of $25 \mathrm{mg}$ of rofecoxib in cardiovascular patients with a diagnosis of colorectal adenoma. APPROVe was a multicentre, randomised, placebo-controlled, double-blind trial. Out of 2586 patients, 1287 were randomised to receive $25 \mathrm{mg}$ rofecoxib and 1299 patients received placebo. 46 patients in rofecoxib group had confirmed thrombotic events in the form of myocardial infarction and cerebrovascular events as compared to 26 patients in the placebo group. The events were similar in the first 18 months in both groups but patients in rofecoxib group had higher risk after 18 months of use [14]. Baron et al., did a final analysis of the patients who had cardiovascular events in the APPROVe trial. They could study $84 \%$ patients. They found on analysis that the patients who were in rofecoxib group had a high risk of cardiovascular events after one year of stopping the treatment [16]. The study done by Nussmeier et al., involved 1671 patients undergoing coronary artery bypass grafting. They recruited and randomized patients to receive parecoxib IV for 3 days followed by oral valdecoxib through day 10 post operative or placebo for 10 days. Standard narcotic medications were accessible to these patients. Patients were followed up for 30 days. They observed that adverse cardiovascular events like myocardial infarction, stroke, cardiac arrest and pulmonary embolism was more common in patients who received valdecoxib and parecoxib (2\% in COX-2 group vs $0.5 \%$ in placebo group) [15].

\section{Discussion}

The result of randomized studies, observational studies and case reports series definitely warrants caution when NSAIDs and specific COX-2 inhibitors are used in patients with cardiovascular diseases. Safety of naproxen has been established by several studies when compared to other NSAIDs. COX-2 inhibitors were developed to 


\begin{tabular}{|c|c|c|c|c|c|}
\hline S. No. & Authors & Type of study & Study & No. of patients studied & Results \\
\hline 1 & Hudson et al. [9] & $\begin{array}{l}\text { Population based retrospective } \\
\text { cohort study }\end{array}$ & $\begin{array}{l}\text { Differences in outcomes } \\
\text { of patients with congestive } \\
\text { heart failure prescribed } \\
\text { COX-II inhibitors or NSAIDs }\end{array}$ & 2256 & $\begin{array}{l}\text { The risk of death and recurrent } \\
\mathrm{CHF} \\
\text { combined was higher in patients } \\
\text { prescribed NSAIDs or rofexocib } \\
\text { than in those prescribed celecoxib }\end{array}$ \\
\hline 2 & Ray et al. [10] & $\begin{array}{l}\text { Multisite retrospective cohort } \\
\text { study }\end{array}$ & $\begin{array}{l}\text { Safety of NSAID in patients } \\
\text { with CAD studied }\end{array}$ & Cohort of 48566 & $\begin{array}{l}\text { Safety profile of naproxen was } \\
\text { better than other NSAIDs and } \\
\text { higher doses of COX-II inhibitors }\end{array}$ \\
\hline 3 & Lindhardsen et al. [11] & Longitudinal cohort study & $\begin{array}{l}\text { Use of NSAID and risk of } \\
\text { cardiovascular diseases in } \\
\text { rheumatoid arthritis patients }\end{array}$ & $\begin{array}{l}17,320 \text { patients (over } 12 \\
\text { years) }\end{array}$ & $\begin{array}{l}\text { Risk was lower than in non RA } \\
\text { patients. Few NSAIDs are } \\
\text { associated with cardiovascular } \\
\text { risk. The use of NSAID should be } \\
\text { individualised. }\end{array}$ \\
\hline 4 & Mcgettigan \& Henry [1] & $\begin{array}{l}\text { Meta analysis of RCTs and } \\
\text { controlled observational } \\
\text { studies }\end{array}$ & $\begin{array}{l}\text { NSAID prone to cardiovas- } \\
\text { cular risk investigated }\end{array}$ & $\begin{array}{l}\text { Data on NSAID prescription } \\
\text { from } 13 \text { countries collected } \\
\text { and analysed }\end{array}$ & $\begin{array}{l}\text { When indicated, low risk drugs like } \\
\text { Naproxen should be used instead } \\
\text { of diclifenac and rofecoxib. }\end{array}$ \\
\hline 5 & Graham et al. [12] & Nested case-conrol study & $\begin{array}{l}\text { Risk of AMI \& sudden } \\
\text { cardiac death due to use of } \\
\text { NSAID \& COX-II inhibitors } \\
\text { investigated }\end{array}$ & $\begin{array}{l}8143 \text { cases occurred after } \\
2302029 \text { person-years follow } \\
\text { up }\end{array}$ & $\begin{array}{l}\text { Rofecoxib increases cardiovas- } \\
\text { cular risk compared to celecoxib. } \\
\text { Naproxen is not absolutely safe. }\end{array}$ \\
\hline 6 & Hippisley-Cox \& Coupland [13] & $\begin{array}{l}\text { Population based nested } \\
\text { case-control study }\end{array}$ & $\begin{array}{l}\text { Risk of MI with the use of } \\
\text { COX-2 inhibitors and NSAID } \\
\text { studied }\end{array}$ & 9218 cases studied & $\begin{array}{l}\text { Significantly increased risk of MI } \\
\text { seen with the use of NSAID \& } \\
\text { Cox-II inhibitors }\end{array}$ \\
\hline 7 & Bresalier et al. [14] & $\begin{array}{l}\text { Long-term, multicenter, } \\
\text { randomized, placebo-con- } \\
\text { trolled, double-blind trial in } 29 \\
\text { countries (APPROVe trial) }\end{array}$ & $\begin{array}{l}\text { Cardiovascular outcomes } \\
\text { associated with use of } \\
\text { Rofecoxib in patients with } \\
\text { colorectal adenoma }\end{array}$ & $\begin{array}{l}2586 \text { patients; } 1287 \text { received } \\
25 \mathrm{mg} \text { Rofecoxib \& } 1299 \\
\text { received placebo }\end{array}$ & $\begin{array}{l}46 \text { patients in Rofecoxib group had } \\
\text { thrombotic events compared to } 26 \\
\text { patients in placebo group }\end{array}$ \\
\hline 8 & Nussmeier et al. [15] & $\begin{array}{l}\text { Randomized, double blind } \\
\text { study involving } 10 \text { days of } \\
\text { treatment and } 30 \text { days of } \\
\text { follow up }\end{array}$ & $\begin{array}{l}\text { To ascertain safety of } \\
\text { Valdecoxib and parecoxib in } \\
\text { patients undergoing CABG }\end{array}$ & $\begin{array}{l}1671 \text { patients randomly } \\
\text { assigned to receive IV } \\
\text { parecoxib for at least } 3 \text { days, } \\
\text { followed by oral valdecoxib } \\
\text { for } 10 \text { days; intravenous } \\
\text { placebo followed by oral } \\
\text { valdecoxib; or placebo for } \\
10 \text { days }\end{array}$ & $\begin{array}{l}\text { Increased incidence of adverse } \\
\text { cardiovascular events observed in } \\
\text { patients receiving valdecoxib and } \\
\text { parecoxib }\end{array}$ \\
\hline
\end{tabular}

Table 2: Review of Literature.

reduce the adverse events by avoiding COX-1 inhibition. But even their safety is not completely proven. There are other associated factors which may be directly or indirectly responsible for the adverse cardiovascular events. Patients with cardiac diseases (coronary artery disease, cardiomyopathies etc.) have per se thrombotic tendencies.

Use of these drugs should be individualized. Elderly patients are more susceptible to cardiovascular adverse events. The studies couldn't come out with the exact dose and the duration of medication which can be taken as a cut off. A thorough history should be taken prior to prescribing these drugs. High risk patients should be warned about the adverse effects and should be instructed to report to the hospital if any warning symptoms are observed. The agents with the least side effect profile should be used (for e.g., Naproxen). Other pain relief medications (paracetamol, oral narcotics ex: tramadol, tapentadol, morphine in combination) can be prescribed in high risk patients.

\section{Conclusion}

Among all the available non-specific NSAIDs and the COX-2 inhibitors, naproxen appears to have the safest profile as far as adverse cardiovascular events are concerned. The clinician should prescribe a drug with safest cardiovascular profile in the lowest dose and for the shortest duration.

\section{References}

1. McGettigan P, Henry D (2013) Use of non-steroidal anti-inflammatory drugs that elevate cardiovascular risk: an examination of sales and essential medicines lists in low-, middle-, and high-income countries. PLoS Med 10: 1001388.

2. Garcia Rodríguez LA (2001) The effect of NSAIDs on the risk of coronary heart disease: fusion of clinical pharmacology and pharmacoepidemiologic data. Clin Exp Rheumatol 19: 41-44.

3. Scheiman JM, Hindley CE (2010) Strategies to optimize treatment with NSAIDs in patients at risk for gastrointestinal and cardiovascular adverse events. Clin Ther 32: 667-677.

4. Olsen AM, Gislason GH, Fosbøl EL (2013) Time-perspective in cardiovascular risk of NSAID use after first-time myocardial infarction. Curr Opin Cardiol 28: 683-688.

5. Howes LG (2007) Selective COX-2 inhibitors, NSAIDs and cardiovascular events - is celecoxib the safest choice? Ther Clin Risk Manag 3: 831-845.

6. Jüni $P$, Reichenbach S, Egger M (2005) COX 2 inhibitors, traditional NSAIDs, and the heart. BMJ 330: 1342-1343.

7. Bleumink GS, Feenstra J, Sturkenboom MC, Stricker BH (2003) Nonsteroidal anti-inflammatory drugs and heart failure. Drugs 63: 525-534.

8. Pawlosky N (2013) Cardiovascular risk: Are all NSAIDs alike? Can Pharm J (Ott) 146: 80-83.

9. Hudson M, Richard H, Pilote L (2005) Differences in outcomes of patients with congestive heart failure prescribed celecoxib, rofecoxib, or non-steroidal anti-inflammatory drugs: population based study. BMJ 330: 1370. 
10. Ray WA, Varas-Lorenzo C, Chung CP, Castellsague J, Murray KT, et al (2009) Cardiovascular risks of nonsteroidal antiinflammatory drugs in patients after hospitalization for serious coronary heart disease. Circ Cardiovasc Qual Outcomes 2: 155-163.

11. Lindhardsen J, Gislason GH, Jacobsen S, Ahlehoff O, Olsen AM, et al. (2013) Non-steroidal anti-inflammatory drugs and risk of cardiovascular disease in patients with rheumatoid arthritis: a nationwide cohort study. Ann Rheum Dis.

12. Graham DJ, Campen D, Hui R, Spence M, Cheetham C, et al. (2005) Risk of acute myocardial infarction and sudden cardiac death in patients treated with cyclo-oxygenase 2 selective and non-selective non-steroidal anti-inflammatory drugs: nested case-control study. Lancet 365: 475-481.
13. Hippisley-Cox J, Coupland C (2005) Risk of myocardial infarction in patients taking cyclo-oxygenase-2 inhibitors or conventional non-steroidal anti-inflammatory drugs: population based nested case-control analysis. BMJ 330 : 1366.

14. Bresalier RS, Sandler RS, Quan H, Bolognese JA, Oxenius B, et al. (2005) Cardiovascular events associated with rofecoxib in a colorectal adenoma chemoprevention trial. N Engl J Med 352: 1092-1102.

15. Nussmeier NA, Whelton AA, Brown MT, Langford RM, Hoeft A, et al. (2005) Complications of the COX-2 inhibitors parecoxib and valdecoxib after cardiac surgery. N Engl J Med 352: 1081-1091.

16. Baron JA, Sandler RS, Bresalier RS, Lanas A, Morton DG, et al. (2008) Cardiovascular events associated with rofecoxib: final analysis of the APPROVe trial. Lancet 372: 1756-1764. 